\title{
ASPECTOS CLIMÁTICOS VERSUS VARIAÇÃO SAZONAL DO PERFIL MORFODINÂMICO DAS PRAIAS DO LITORAL OESTE DE AQUIRAZ, CEARÁ, BRASIL
}

\author{
MOURA, Marisa Ribeiro - marisageog@yahoo.com.br \\ UFC - Universidade Federal do Ceará
}

\begin{abstract}
RESUMO
A presente pesquisa analisou nas praias do litoral oeste de Aquiraz, Ceará, os processos que regem a geomorfologia costeira (parâmetros climatológicos, morfológicos e oceanográficos), a fim de verificar como estes influenciam nesta, provocando mudanças na morfodinâmica da praia. Foram realizadas coletas de dados nos anos de 2007-2008 para a caracterização climática, nas PCDs da FUNCEME, do CPTEC/INPE e do INMET, além de dados coletados em trabalhos de campo. O litoral apresentou variações sazonais diferenciadas onde maior índice de umidade deu-se no período chuvoso com média de $90 \%$. A temperatura local não apresentou grandes variações anuais, sendo o mês de dezembro o mais quente $\left(31^{\circ} \mathrm{C}\right)$, e o de julho o mais frio $\left(23^{\circ} \mathrm{C}\right)$. As marés tiveram amplitude máxima alcançada de $3,0 \mathrm{~m}$ e mínima de $1,1 \mathrm{~m}$. Durante o monitoramento $75 \%$ das ondas sea apresentaram período entre 6 e 9 s. A direção predominante dos ventos foi de SE-NO, com velocidade média de $3,5 \mathrm{~m} / \mathrm{s}$. As maiores foram registradas entre os meses de agosto e novembro atingindo médias de $5,5 \mathrm{~m} / \mathrm{s}$. A variação sazonal do perfil apontou uma mudança relacionada principalmente com a declividade da praia nos períodos chuvoso e de estiagem, mostrando que as condicionantes oceanográficas e climatológicas influenciaram na configuração da linha de costa.
\end{abstract}

Palavras-chave: parâmetros climáticos, faixa de praia, dinâmica costeira, Aquiraz.

CLIMATE ASPECTS VERSUS SEASONAL MORPHODYNAMIC PROFILE OF THE WEST COAST BEACHES OF AQUIRAZ, CEARÁ, BRAZIL

\section{ABSTRACT}

This research examined the beaches in of the west coast of Aquiraz (Ceará/Brazil), the processes governing the coastal geomorphology (climatological, morphological and oceanographic parameters), to verify how this influence in this, causing changes in the morphodynamics of the beach. Were realize data collected in the years 2007-2008 to characterize climate in the PCDs of the FUNCEME, CPTEC/INPE and the INMET, and data collected in fieldwork. The coast showed different seasonal variation where higher moisture content occurred in the rainy season with an average of $90 \%$. The local temperature did not show large annual variations, where the month of december the warmest $\left(31^{\circ} \mathrm{C}\right)$ and july the coldest $\left(23^{\circ} \mathrm{C}\right)$. The tides had reached maximum amplitude of $3.0 \mathrm{~m}$ and a minimum of $1.1 \mathrm{~m}$. During monitoring $75 \%$ of sea waves had time between 6 and $9 \mathrm{~s}$. The wind direction was SE-NO, with an average speed of $3.5 \mathrm{~m} / \mathrm{s}$. The highest were recorded between august and november averaged $5.5 \mathrm{~m} / \mathrm{s}$. The seasonal variation of the profile showed a change related primarily to the beach slope in rainy and dry seasons, showing that the oceanographic and climatic conditions influence the configuration of the coastline.

Keywords: climatic parameters, strip of beach, coastal dynamics, Aquiraz.

\section{INTRODUÇÃO}

Este estudo foi proposto devido sabermos que as praias são ambientes que representam importantes áreas recreacionais em torno das quais se desenvolvem cidades, balneários, atividades turísticas, comerciais e industriais. 
Contudo, é notório que essas atividades sobre os ecossistemas do litoral tenha tornado as zonas costeiras ambientes de grande tensão ambiental. Com base nisso, ações gestoras passaram a ser desenvolvidas tendo por meta a utilização integrada dos recursos naturais disponíveis na planície litorânea.

Os elementos climáticos constituem as principais variáveis que controlam e transformam os processos costeiros. Dentre estes elementos podemos destacar a variação mensal e anual dos totais pluviométricos e o regime dos ventos. Ayoade (1991) afirma que, "os processos atmosféricos influenciam os processos nas outras partes do ambiente, principalmente na biosfera, hidrosfera e litosfera". Desta forma todas as outras partes do ambiente influenciarão e serão influenciados pelo clima.

Para Muehe (1996) os elementos hidrodinâmicos e climatológicos são os principais fatores de modelagem das zonas costeiras, isto é, o perfil transversal de uma praia varia com ganho ou perda de areia de acordo com a energia das ondas e da fonte de suprimento sedimentar. Já Woodroffe (2002) afirma que o vento é um importante fator responsável pela formação das ondas e marés, além de influenciar na modificação e desenho das costas. $E$ de acordo com Hoefel (1998), as marés são elementos importantes a serem considerados, pois sua oscilação interfere na morfologia das praias.

O clima por ser responsável pelos regimes meteorológicos, envolvendo temperatura, precipitações, ventos, ondas, correntes litorâneas, tempestades etc., exerce grande influência sobre as características geomorfológicas das regiões costeiras. O controle da direção e poder energético das ondas que batem na linha de costa produzindo as correntes litorâneas que transportam sedimentos em diferentes sentidos é um exemplo importante deste condicionamento relacionado com a morfodinâmica praial.

A presente pesquisa teve como objetivo analisar nas praias do litoral oeste de Aquiraz, Ceará, os processos que regem a geomorfologia costeira (parâmetros climatológicos, morfológicos e oceanográficos), a fim de verificar como estes influenciam nesta, provocando mudanças na morfodinâmica da praia.

O município de Aquiraz localiza-se na porção nordeste do Estado do Ceará, e ocupa uma área de 48,97 $\mathrm{Km}^{2}$, a uma altitude de 14,23m (IBGE, 2000). A área em estudo corresponde à parte oeste do litoral de Aquiraz, mais especificamente as praias do Porto das Dunas, Japão e Prainha (Fig. 1), que possui aproximadamente $13 \mathrm{~km}$ de extensão. 


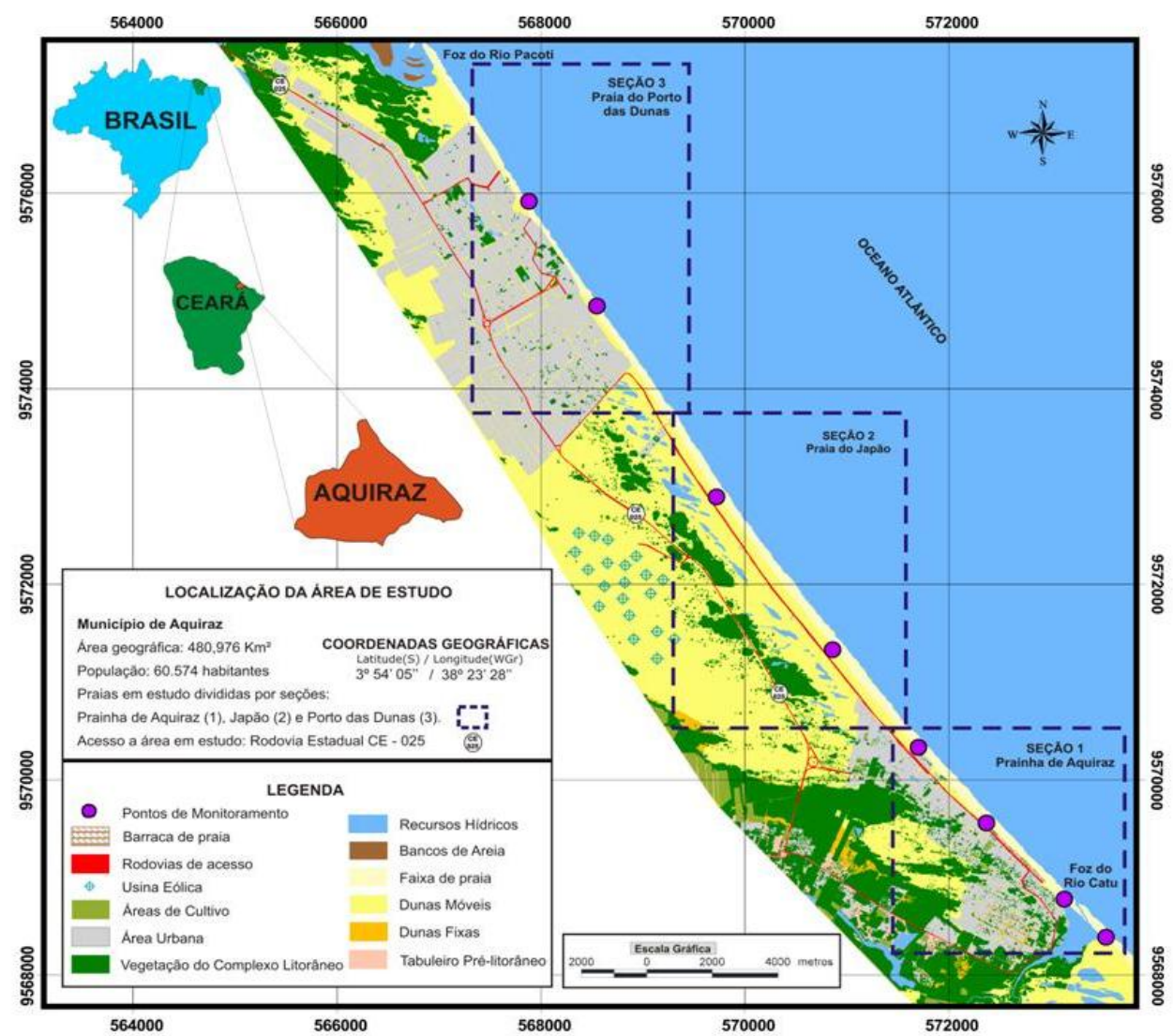

Fig. 1: Mapa de localização do litoral oeste de Aquiraz. Fonte: Moura, 2009.

\section{PROCEDIMENTOS METOdOLógICOS}

Para um estudo mais aprofundado acerca dos elementos climáticos, foram coletados para a análise das características climáticas do município de Aquiraz, dados das Plataformas de Coleta de Dados (PCDs), instaladas pela Fundação Cearense de Meteorologia e Recursos Hídricos - FUNCEME, pelo Centro de Previsão de Tempo e Estudos Climáticos - CPTEC/INPE e informações do Instituto Nacional de Meteorologia - INMET, além de dados coletados nos trabalhos de campo, utilizando um anemômetro manual, que coleta dados sobre a velocidade dos ventos e a temperatura local. 
Os estudos de climatologia são estruturados em elementos climáticos e fatores geográficos do clima. Os elementos climáticos são constitutivos do clima e compreendem a temperatura, a umidade e a pressão atmosférica, que se manifestam por meio de precipitação, vento, nebulosidade e ondas de calor e frio, por exemplo. A variação desses três elementos nas diferentes localidades e momentos depende principalmente, dos fatores do clima, ou controles climáticos, que são a latitude, a altitude, o relevo, a maritimidade, a continentalidade, a vegetação e as atividades humanas (MENDONÇA et al., 2007).

Para a análise dos parâmetros oceanográficos foram utilizados dados da tábua de maré dos dois anos de monitoramento (2007-2008), cedida pela Diretoria de Hidrografia e Navegação (DHN) para a geração de dados estatísticos sobre a amplitude da maré e os períodos possíveis de ressacas no litoral em causa e, nos trabalhos de campo foram feitas coletas de dados sobre o clima de ondas, marcando sua direção, predominância tipológica, altura e frequência.

Para acompanhar a variação da morfologia da praia foram demarcados oito pontos de monitoramento visando locais onde os processos erosivos e as ocupações da praia estão em maior número. Seguindo os métodos de Morais (1996), Muehe (1996) e Emery (1961) foram realizados a cada dois meses, trabalhos de campo, onde foram feitos perfis topográficos perpendiculares à linha da costa. Para avaliar os estágios morfodinâmicos dos ambientes praiais, utilizou-se o cálculo do parâmetro de Dean $(\Omega)$, metodologia proposta por Wright e Short (1984). De acordo com esses parâmetros as praias arenosas foram classificadas em dissipativas (de baixa energia) e refletivas (de alta energia) e mais quatro estágios intermediários.

\section{RESULTADOS E DisCusSõES}

Na busca de definir uma melhor forma de planejamento e uso do litoral oeste de Aquiraz, investigamos as características fisiográficas que definem o mesmo. Neste sentido, um estudo mais detalhado sobre os sistemas controladores que influenciam diretamente na dinâmica costeira se torna indispensável, já que são eles - aspectos climáticos, vento, ondas, marés e correntes costeiras - que atuam de forma direta em conjunto com as atividades humanas, provocando mudanças da linha de costa.

\section{ASPECTOS CLIMÁtICOS}


O clima do litoral cearense apresenta como característica principal uma pluviometria tropical do tipo semiárido, com duas estações bem diferenciadas, sendo uma com precipitações de curtas durações e outra com uma estiagem prolongada. O litoral de Aquiraz não foge a regra, apresentando dois períodos climáticos bem definidos (Gráf. 1).

De acordo com a metodologia de Xavier (2001), os anos de 2007 e 2008 foram anos denominados habituais, pois ambos, em suas quadras chuvosas, tiveram precipitações de 1.028,1 e 1.003,6 mm respectivamente (Graf. 2).

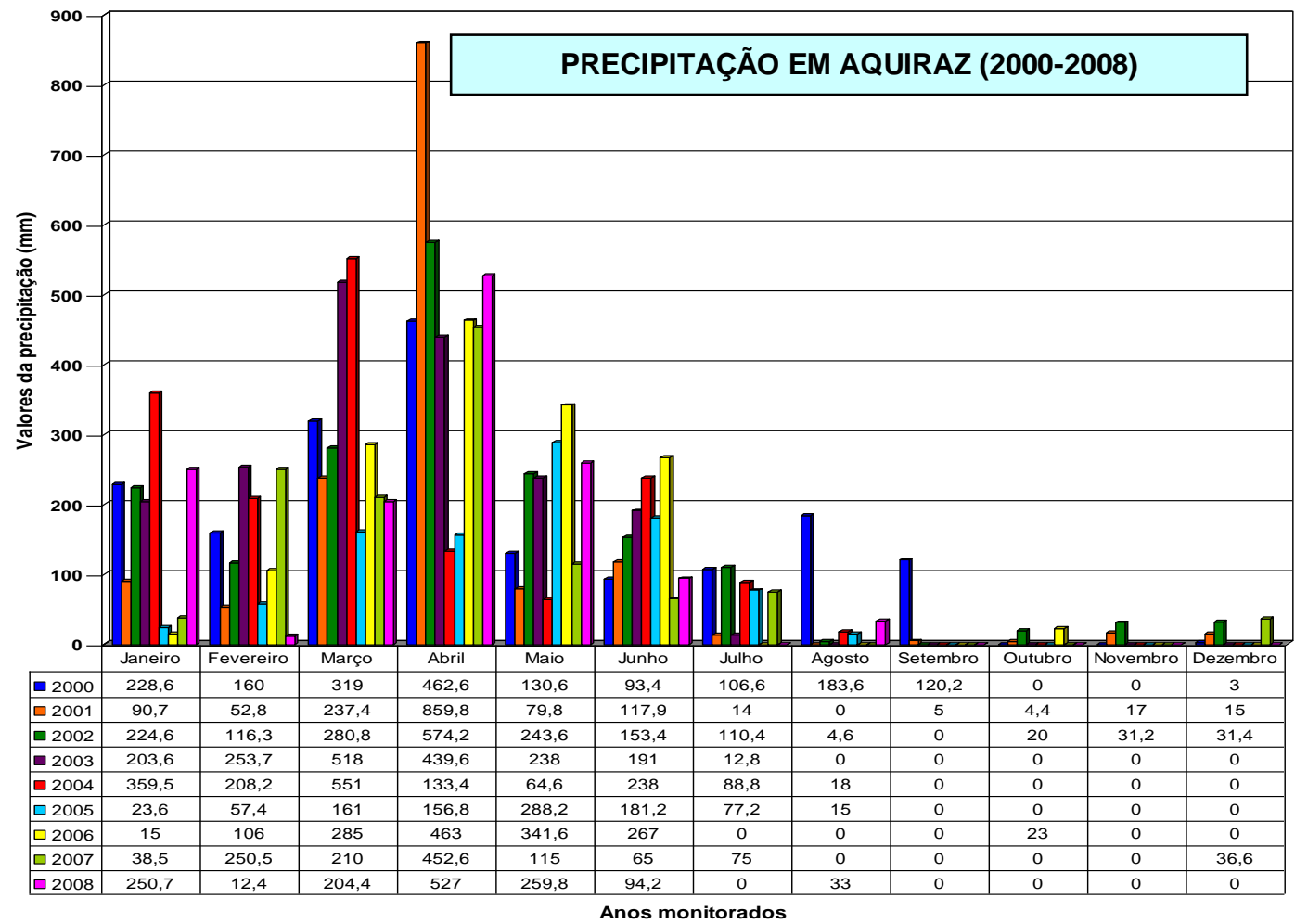

Gráf. 1: Distribuição da precipitação média anual durante os anos de 2007-2008. Fonte: FUNCEME.

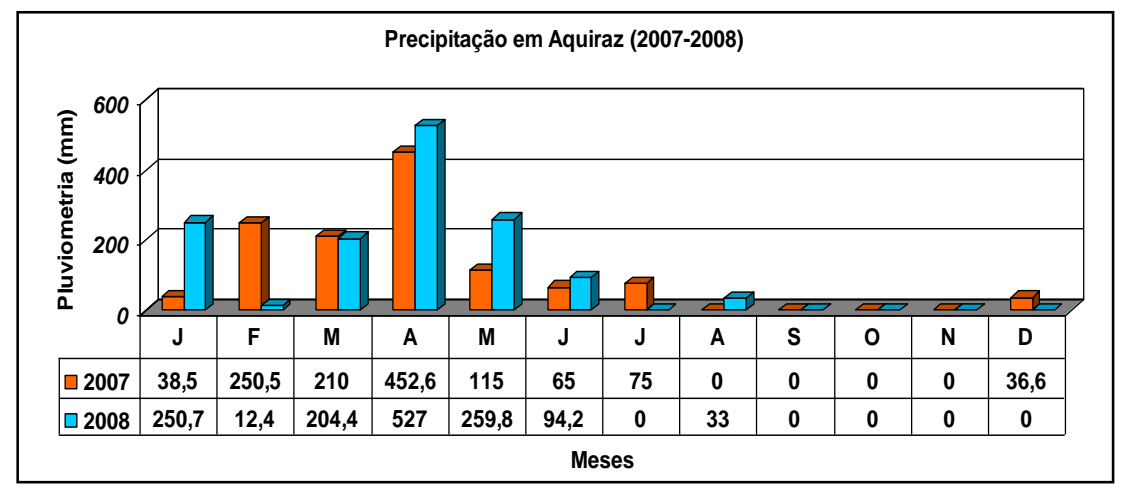

Gráf. 2: Distribuição da precipitação média anual durante os anos de 2007-2008. Fonte: FUNCEME. 
A série dos dados coletados vai desde o ano de 1979 a 2008, totalizando 29 anos de coleta de informações pluviométricas. A média anual de chuvas em Aquiraz foi de $1.250 \mathrm{~mm}$ com valor máximo de $1.941,1 \mathrm{~mm}$ em 1988 e mínimo de 722,1 mm em 1998. Verificamos também que nos últimos 29 anos a precipitação no município de Aquiraz seguiu a tendência de períodos chuvosos no primeiro semestre do ano e períodos de estiagem no segundo semestre, como podemos ver no gráfico abaixo (Gráf. 3).

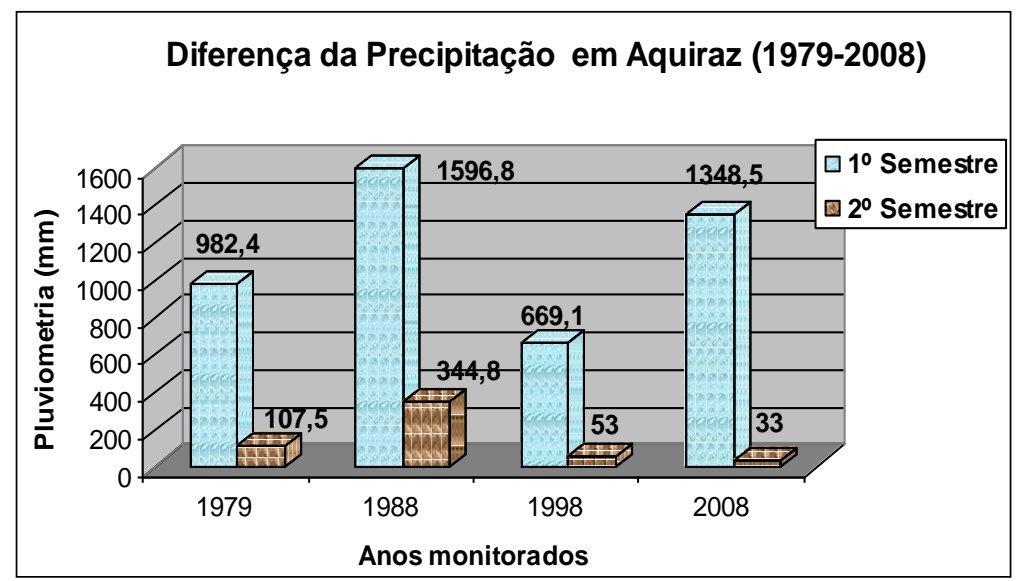

Gráf. 3: Distribuição da precipitação média anual durante o período de 1979-2008. Fonte: FUNCEME.

Vale destacar que a variação anual da pluviometria é controlada pelo movimento da ZCIT, que são observadas nas proximidades da linha do Equador e que, de acordo com Souza (2000), o sistema é gerado pela convergência dos ventos alísios de NE no hemisfério norte, e de SE no hemisfério sul. Dependendo da sua posição e tempo de permanência estes podem gerar anos com maiores ou menores precipitações, sendo as mínimas representações das secas que geralmente estão relacionadas com a atuação dos fenômenos do El Niño e da $L a$ Niña.

O gráfico abaixo mostra que a umidade relativa do ar depende das informações pluviométricas, pois os meses com maior pluviometria foram relativamente aqueles com maior umidade, enquanto que os meses nos períodos de estiagem apresentaram menores valores (Gráf. 4). O maior índice de umidade ocorreu em março de 2007 com média de $90 \%$ e a menor umidade foi verificada no mês de setembro de 2008 , com média de $49,6 \%$.

Em virtude da localização geográfica da área em estudo, caracterizada pela baixa latitude e a ausência de fatores geográficos influenciadores, a temperatura 
local não apresenta grandes variações anuais ou mensais; as máximas das médias variam entre $28^{\circ} \mathrm{C}$ e $31^{\circ} \mathrm{C}$, ocorrendo no fim do período de estiagem. Os meses de outubro, novembro e dezembro apresentam as maiores temperaturas, já as menores registram-se em maio, junho e julho. A média de dezembro, mês mais quente, é de $31^{\circ} \mathrm{C}$, e em julho, mês mais frio, é de $23^{\circ} \mathrm{C}$ (FUNCEME). O gráfico abaixo mostra a relação da precipitação com a temperatura local, onde podemos observar que a temperatura diminui na medida que aumenta a precipitação e vice-versa (Gráf. 5).

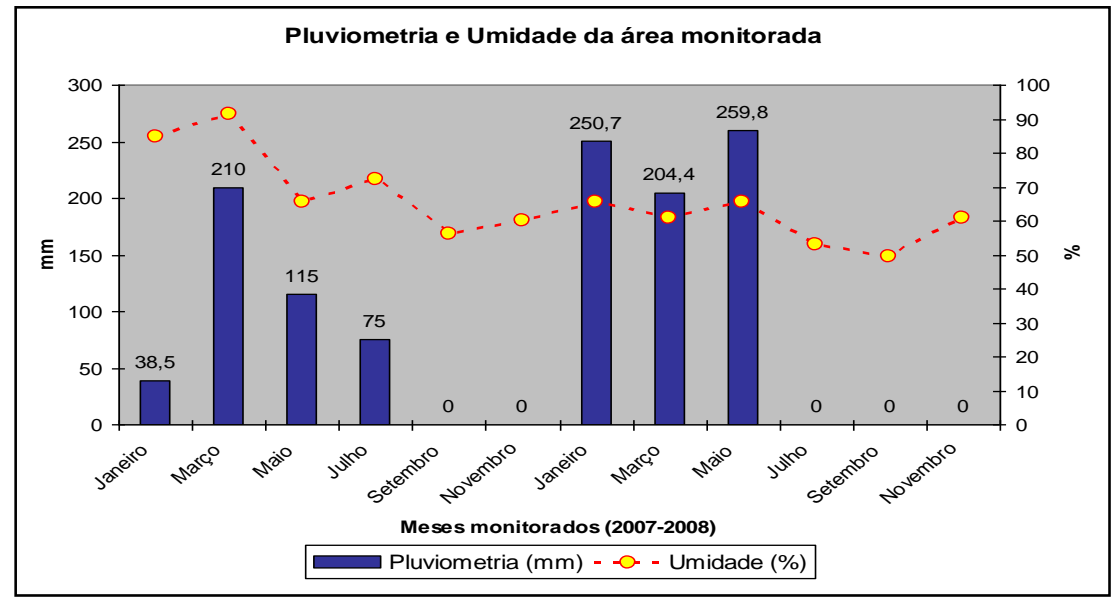

Gráf. 4: Umidade relativa do ar e sua relação com a pluviometria da área em foco. Fonte: FUNCEME.

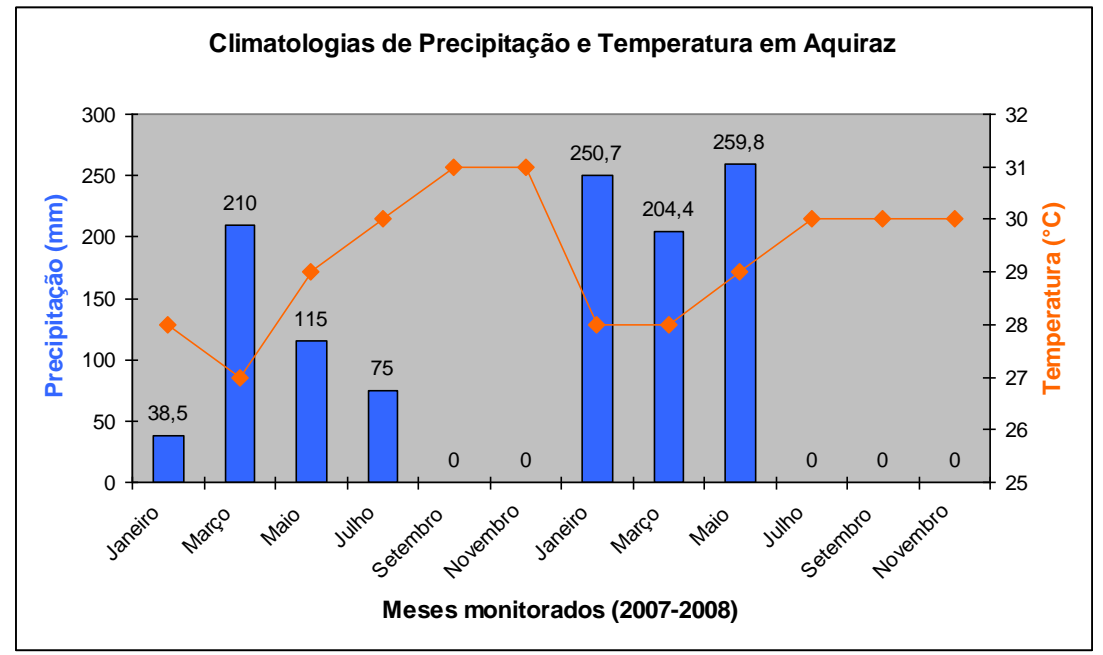

Gráf. 5: Relação precipitação versus temperatura em Aquiraz. Fonte: CPTEC/INPE. 
Segundo Ayoade (1991, p. 27), "os fatores que identificam a quantidade de radiação recebida em determinado local são gerados pela duração do dia, pela latitude da Terra e pela altitude e distância do Sol". Sendo assim, por se localizar próximo a linha do Equador, o litoral de Aquiraz possui suas máximas de insolação no período dos equinócios e as míninas nos solstícios.

No que diz respeito à insolação da área, o valor médio diário é de 8 horas, atingindo valor superior ao de 9 horas de setembro a novembro e tem valor mínimo ocorrendo geralmente em março, que varia de 6 a 7 horas de sol/dia (FUNCEME). O trimestre fevereiro/março/abril, apresenta os menores valores devido ser o período mais chuvoso. A média anual é de aproximadamente 3.000 horas/sol (Gráf. 6).
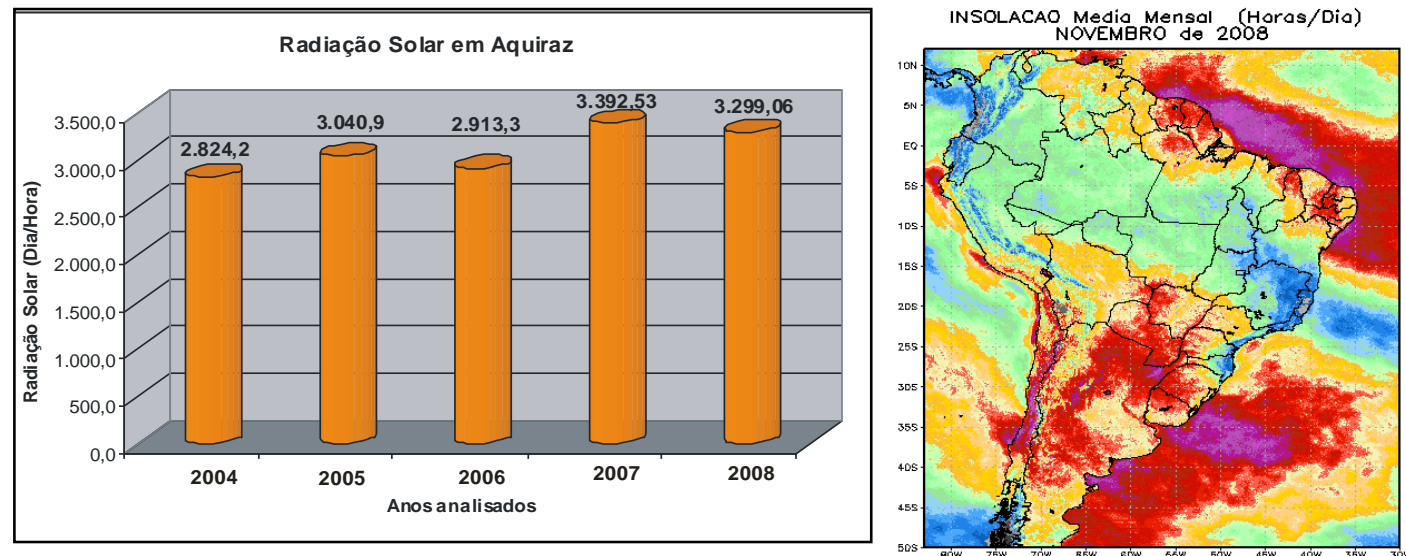

Gráf. 6: Valores anuais das médias de insolação em Aquiraz, entre 2004-2008. Fonte: CPTEC/INPE.

Devido à elevada taxa de insolação nas áreas litorâneas, as médias mensais de evaporação também são bastante elevadas, totalizando aproximadamente 1700 milímetros durante o ano, com períodos máximos durante os meses de setembro a novembro e mínimos entre fevereiro e abril.

A evaporação, conforme Ayoade (1991, p. 129) pode ser determinada a partir da "(...) disponibilidade de umidade na superfície onde há evaporação" e é gerada "(...) em função de diversos fatores, incluindo a radiação solar, a temperatura, a velocidade do vento e a umidade". Em se tratando de Aquiraz, o aumento da evaporação se deu em decorrência do aumento de insolação e queda da velocidade do vento em determinados meses do ano, como mostra o gráfico abaixo, cevando em consideração os dados de Fortaleza (Gráf. 7).

Podemos afirmar que o vento é um dos fatores climáticos que mais interfere nos parâmetros até então citados. Este interfere na taxa de evaporação, que modificando a temperatura, movimenta as nuvens que são responsáveis pela 
precipitação pluviométrica dentre outros. Porém um grande papel do vento nas zonas costeiras, e em específico na área em estudo, é na formação dos campos de dunas e a alimentação destes.

Verificamos que a direção predominante dos ventos na área em estudo em grande parte do ano é de sudeste para noroeste. Contudo, os alísios de nordeste ocorrem apresentando menor velocidade durante os meses de janeiro a maio. A velocidade média é de $3,5 \mathrm{~m} / \mathrm{s}$, os menores valores ficam em torno de $1,5 \mathrm{~m} / \mathrm{s}$ e $2,3 \mathrm{~m} / \mathrm{s}$ e ocorrem entre os meses de fevereiro a maio, coincidindo com a quadra chuvosa. As maiores velocidades são registradas entre os meses de agosto a novembro atingindo médias diárias de $5,5 \mathrm{~m} / \mathrm{s}$ (Gráf. 8).

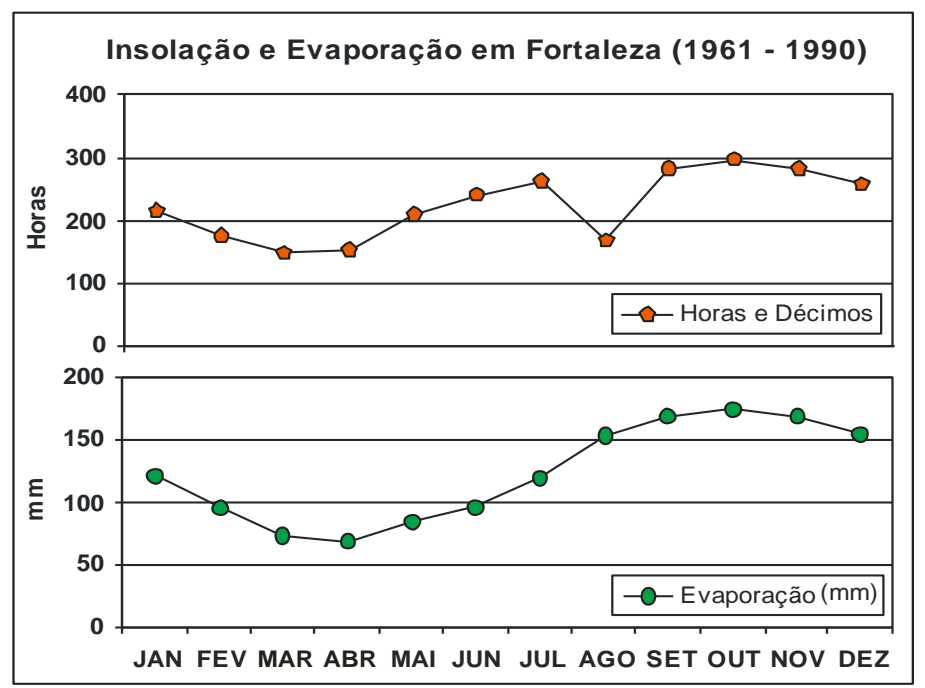

Gráf. 7: Taxa de insolação e evaporação em Fortaleza. Fonte: INMET.

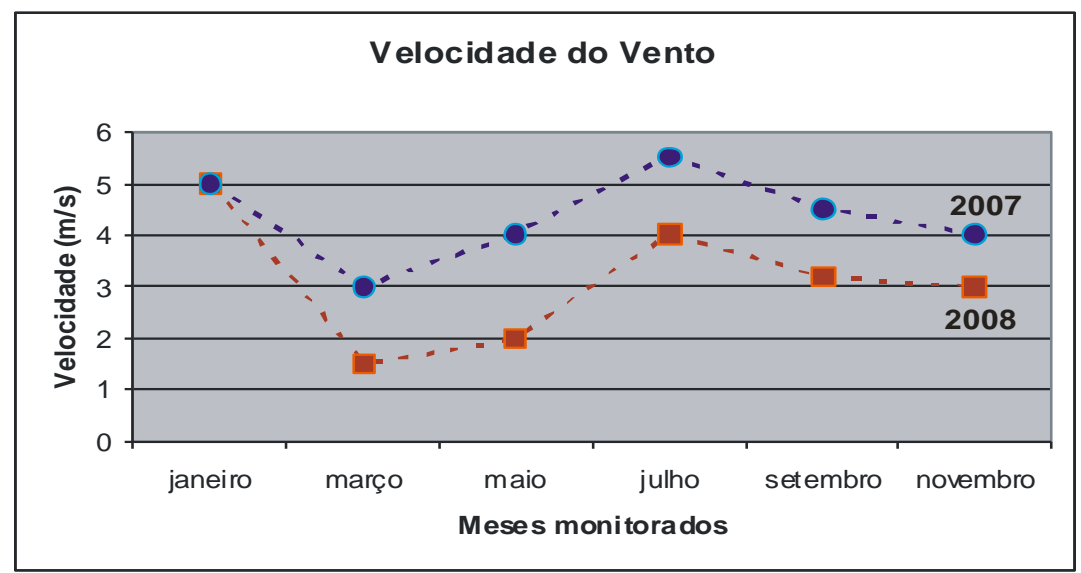

Gráf. 8: Velocidade do vento no litoral de Aquiraz (2007 - 2008). Fonte: CPTEC/INPE. 


\section{ASPECTOS OCEANOGRÁFICOS}

Para o estudo específico dos fatores que regem a geomorfologia costeira é necessária a distinção sedimentológica e sua mobilidade em função de parâmetros hidrológicos e oceanográficos (ondas, correntes e marés). Neste sentido, são imprescindíveis explicações acerca dos fatores que influenciam os parâmetros oceanográficos para que haja um melhor entendimento da área.

As marés do litoral cearense, mais especificamente para o Porto do Mucuripe em Fortaleza, são do tipo semidiurna, ocorrendo duas preamares e duas baixamares em um dia ( $24 \mathrm{~h}$ e 50 minutos). As amplitudes destas estão subordinadas a atração gravitacional e o alinhamento entre Terra, Lua e Sol. Villes \& Spencer (1995) apud Pinheiro (2000) afirma que quando a Terra, a Lua e o Sol estão alinhados (lua nova e cheia), as variações de marés são cerca de $20 \%$ maior que a média. Nestes períodos as marés observadas são chamadas de marés de sizígia.

O gráfico 9 apresenta os valores das amplitudes de marés mensais registradas no Porto do Mucuripe entre os anos de 2007 e 2008. A amplitude máxima alcançada foi de 3,0 m no mês de maio/2008 e a mínima de $1,1 \mathrm{~m}$ no mês de janeiro/2007. No ambiente costeiro, a amplitude da maré pode ser a causadora de profundas modificações no processo de sedimentação do litoral, seja acumulando ou erodindo a costa.

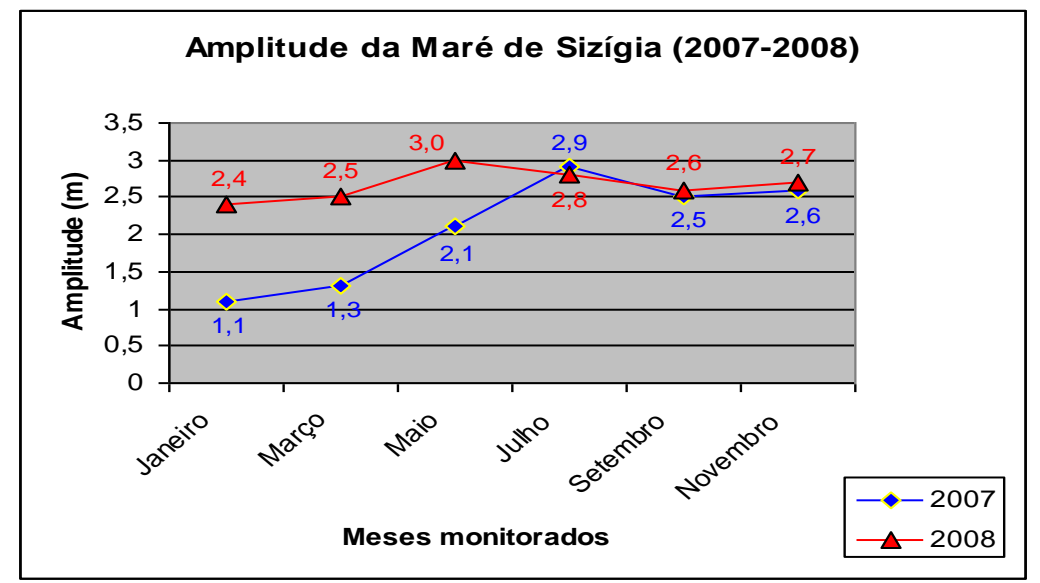

Gráf. 9: Amplitudes mensais das marés registradas para o Porto do Mucuripe. Fonte: DHN.

As correntes litorâneas transportam os sedimentos que são colocados em movimento pela ação das ondas. Este movimento de areia é denominado deriva 
litorânea e constitui-se num processo significativo de transportes de sedimentos ao longo das costas arenosas. Na área em foco foram identificados alguns pontos que se caracterizavam pela presença de correntes de retorno, com cavas e bancos de areia nas zonas de antepraia nas três seções.

A caracterização das ondas foi baseada em observações feitas em campo e na análise dos dados obtidos no Porto do Mucuripe. A morfologia depende da atuação das ondas que são responsáveis pela energia dissipada sobre a praia, provocando a erosão, transporte e a deposição de sedimentos. O gráfico 10 mostra o clima de ondas dos pontos monitorados diferenciando a frequência das ondas entre o período chuvoso e de estiagem.

O histograma também mostra que durante o monitoramento $75 \%$ das ondas apresentaram período entre 6 e 9 segundos (Gráf. 11). Isto significa que as ondas sea são predominantes. A entrada de ondas do tipo swell no litoral de Aquiraz foi verificada no final de setembro de 2007 até março de 2008, esses dados equipararam-se com os registrados no Porto do Mucuripe. O período de ondas foi maior nos meses de março e maio de 2007 e decresceu nos meses subseqüentes, voltando a aumentar em março de 2008.

As ondas que banham o litoral leste e Fortaleza apresentam um forte componente deste com direções variando entre os quadrantes E, ENE e ESE mantendo uma estreita relação com as direções predominantes dos ventos.

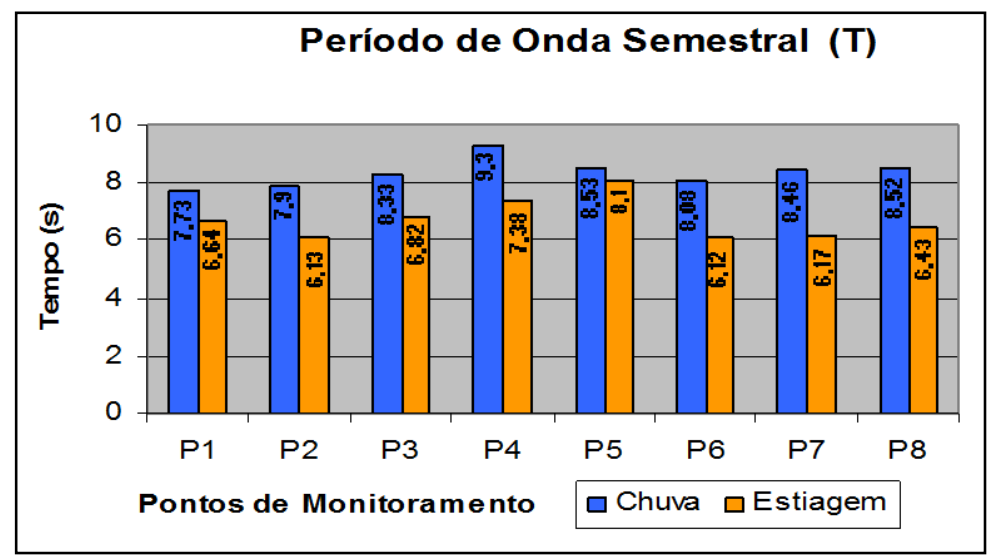




\begin{tabular}{|c|c|c|c|c|c|c|c|c|c|c|}
\hline \multicolumn{7}{|c|}{ Altura média das ondas nas seções de monitoramento (Hb) } \\
\hline \multirow{3}{*}{} & \multicolumn{9}{|c|}{ Ano 2007} & \multicolumn{5}{c|}{ Ano 2008} \\
\cline { 2 - 10 } & Março & Maio & Julho & Setembro & Novembro & Março & Maio & Julho & Setembro & Novembro \\
\hline 01 & 0,5 & 0,6 & 0,6 & 0,8 & 0,9 & 0,6 & 0,6 & 0,5 & 0,8 & 1,5 \\
\hline 02 & 0,6 & 0,5 & 0,5 & 1,1 & 1 & 0,6 & 0,7 & 0,6 & 0,8 & 1,1 \\
\hline 03 & 0,5 & 0,5 & 0,6 & 1 & 1,1 & 0,5 & 0,6 & 0,6 & 0,9 & 1,2 \\
\hline
\end{tabular}

Gráf. 10: Variação da onda nos dois anos monitorados. Fonte: Dados obtidos em campo, (2007-2008).

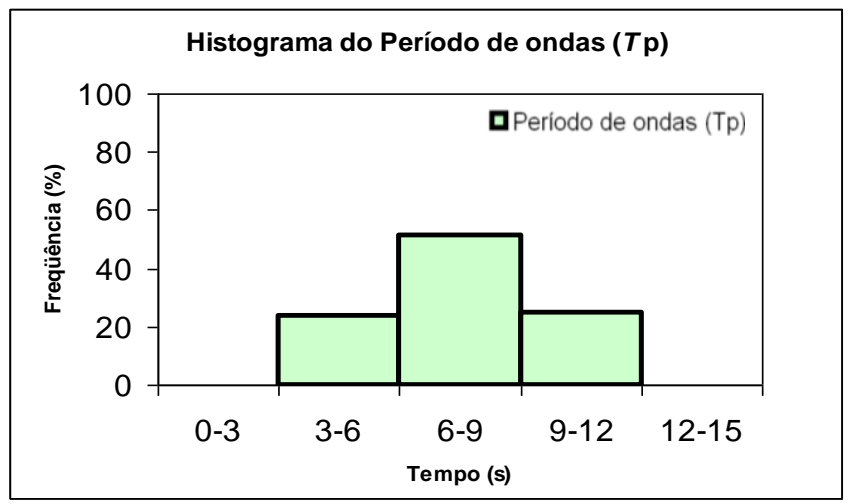

Gráf. 11: Histograma do período de ondas. Fonte: Dados obtidos campo (2007-2008).

\section{ASPECTOS MORFODINÂMICOS}

Os resultados sobre a morfodinâmica nos permitiram compreender e avaliar a rapidez com que os processos costeiros atuam na área. O perfil da faixa de praia diferenciou-se em extensão, variando de $80 \mathrm{~m}$ a $180 \mathrm{~m}$ em alguns pontos, devido às formas de ocupação existentes no local e as variações climáticas ao longo dos dois anos observados.

A variação sazonal do perfil (Fig. 2) apontou uma mudança relacionada principalmente com a declividade da praia nos períodos chuvoso e de estiagem, mostrando que as condicionantes oceanográficas e climatológicas influenciam na configuração da costa. Verificou-se em certos períodos mudanças na inclinação da zona de berma, ocorrendo em pontos específicos escarpas com altura média de 1 a 2 m, causando escavações em diversas barracas localizadas na Prainha. Vale ressaltar a presença de uma larga pós-praia, principalmente na praia do Japão, com aproximadamente 40 m, encontrando vegetação rasteira em toda a área. 
Com relação aos estágios modais das praias obtidos por meio do parâmetro de Dean, mostraram percentuais de $51,38 \%$ para estágios intermediários, $25 \%$ para estágios refletivos e $23,61 \%$ para estágios dissipativos.

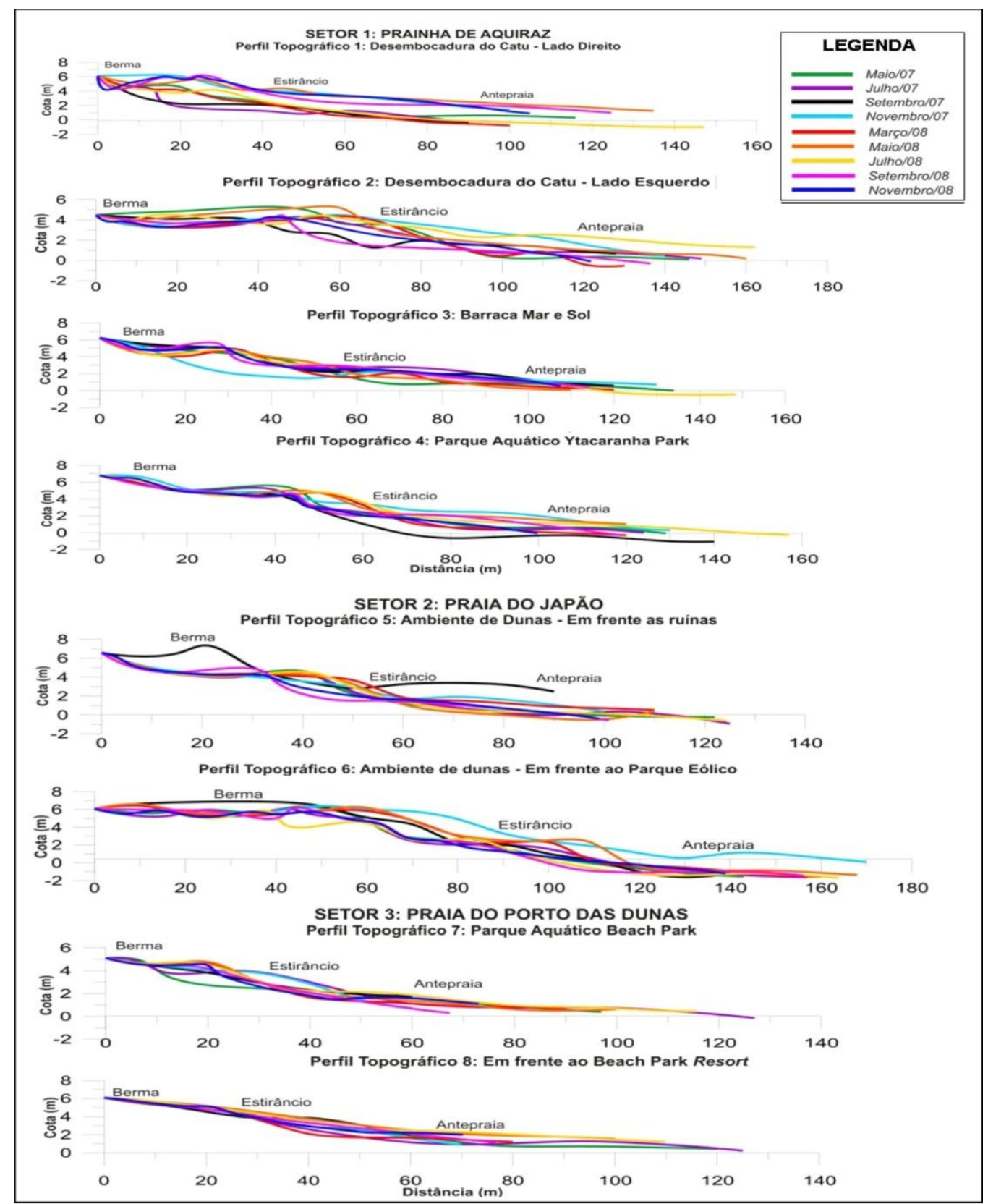

Fig. 2: Variação dos perfis topográficos. Fonte: Dados obtidos em trabalho de campo, (2007-2008). 


\section{CONSIDERAÇõES FINAIS}

Podemos concluir que a dinâmica costeira da área se encontra submetida a fortes pressões das diversas atividades humanas, tendo em destaque o turismo e a urbanização, que alteram de forma significativa os ecossistemas encontrados na planície litorânea de Aquiraz. Esta ocasiona mudanças na circulação dos elementos do sistema Terra-Oceano-Atmosfera, aumentando a tendência de recuo da linha de costa, devido o uso inadequado da planície litorânea, bem como a ocupação da berma e dunas, que alteram o suporte sedimentar do local.

A tendência de perfis menos volumosos com relação à redução dos sedimentos na praia foi observada no período, devido à diminuição da velocidade do vento e consequente baixa das ondas na zona de antepraia. Verificou-se que nos períodos de estiagem, houve um aumento da taxa de evaporação da área, consequência da diminuição das chuvas e do aumento da incidência de raios solares, causando dessa forma o aumento do transporte eólico, mudando assim o desenho da faixa de praia, tornando menos aplainada.

A variação sazonal do perfil morfodinâmico das praias analisadas apontou uma mudança relacionada principalmente com a declividade da praia nos períodos chuvoso e de estiagem, mostrando que as condicionantes oceanográficas e climatológicas influenciam na configuração da costa.

\section{AGRADECIMENTOS}

Nós agradecemos a FUNCAP pelo apoio financeiro, ao LGCO pelo apoio logístico com equipamentos e transportes para campo, a equipe de bolsistas que participaram da pesquisa e aos que auxiliaram no referencial teórico, como a professora Maria Elisa Zanella e os colegas da disciplina de Clima Urbano.

\section{REFERÊNCIAS BIBLIOGRÁFICAS}

AYOADE, J. O. Introdução à Climatologia para os trópicos. 3a edição, Ed. Bertrand Brasil, Rio de Janeiro, 1991.

DHN - 2008 - Tábua de Marés. Diretoria de Hidrografia e Navegação - Marinha do Brasil.

EMERY, K. O. A Simple Method of Measuring Beach Profiles. Limnology and Oceanography. 6 (1): 90-93, 1961. 
FUNCEME. Fundação Cearense de Meteorologia e Recursos Hídricos Meteorologia e Oceanografia: www.funceme.br/DEMET, 2007.

HOEFEL, F. G. Morfodinâmica de Praias Arenosas Oceânicas - Uma Revisão Bibliográfica. Faculdade de Ciências do Mar - FACIMAR, Editora UNIVALI, 92p. 1998.

IBGE. Instituto Brasileiro de Geografia e Estatística-Censo Demográfico, 2000.

MENDONÇA, F.; DANNI-OLIVEIRA, I. M. Climatologia: Noções básicas e climas do Brasil. São Paulo: Oficina de Textos, 2007.

MORAIS, J. O. de. Processos e Impactos Ambientais em Zonas Costeiras. Revista de Geologia da UFC, Fortaleza-CE, v.9, p 191-242, 1996.

MOURA, M. R. Processos costeiros e evolução da ocupação nas praias do litoral oeste de Aquiraz, Ceará entre 1970-2008. Fortaleza: UECE, 2009 (Dissertação de Mestrado); inédita

MUEHE, D. Geomorfogia Costeira. In: Guerra, A. J. T.; Cunha,S. B. (Org). Geomorfologia: exercícios, técnicas e aplicações. 2a edição, 191-238, Edit. Bertrand Brasil, Rio de Janeiro (RJ),1996.

PINHEIRO, L. S. Compatibilização dos Processos Morfodinâmicos e Hidrodinâmicos com o uso e ocupação da praia da Caponga-Cascavel-CE. Dissertação de Mestrado. Universidade Estadual do Ceará, Fortaleza, 2000.

SHORT, A. D.; WRIGHT, L. D. Morphodynamics of high energy beaches - an Australian perspective. In: B.G. Thom (ed.), Coastal Geomorphology in Australia, Academic Press, 43-68, 1984.

WOODROFFE, C. D. Coasts: form, process and evolution. School of Geociences, University of Wollongong, NSW 2522, Austrália, Cambridge University Press, 623p., 2002.

XAVIER, T. de M. B. S. Tempo de chuva - Estudos Climáticos e de Previsão para o Ceará e Nordeste Setentrional. Fortaleza, ABC Editora, 2001. 